\title{
Physical, behavioral and sociodemographic determinants of hypertension among the adult population in Nekemte town, western Ethiopia: community based study
}

\author{
Gemechis Teshome Geleta ${ }^{2}$, Melese Chego Cheme ${ }^{1^{*}}$ (I) and Elias Merdassa Roro ${ }^{1}$
}

\begin{abstract}
Objectives: Hypertension is a growing public health problem in many developing countries. However, there is an insufficiency of scientific evidence on the prevalence of hypertension (HTN) at a community level in the study area. The aim of the study was exploring the prevalence and associated factors of hypertension among adults in Nekemte town, Ethiopia. A community-based cross-sectional study was conducted on 711 adults who were selected by the multistage sampling procedure. Height, weight, blood pressure and waist circumference were measured with standard procedures. Data were analyzed by statistical package for social sciences (SPSS) version 20, and multiple logistic regression model was used to determine the independent risk factors for hypertension.
\end{abstract}

Result: The overall prevalence of hypertension was 34.9\% among the adult population. Of them, only $52.7 \%$ know their status, and $22.4 \%$ were on antihypertensive medication. The prevalence of hypertension was higher among the older aged; AOR 5.85 (95\% Cl 1.74-20), Obese and over-weighted; (AOR 1.71 (95\% Cl 1.09-2.67)), Khat chewers in the past year; AOR 2.44 (95\% Cl 1.05-5.68), and with higher formal education (college and above); AOR 2.75 (95\% Cl 1.26-6.03) than their respective counterparts. Community-level prevention and treatment of hypertension should get due attention.

Keywords: Hypertension, Nekemte, Ethiopia

\section{Introduction}

WHO defines hypertension as systolic blood pressure $\geq 140 \mathrm{mmHg}$ or a diastolic blood pressure $\geq 90 \mathrm{mmHg}$ or prior diagnosis of hypertension and taking antihypertensive drugs [1-3]. About $80-90 \%$ of hypertension is primary hypertension and has no known cause. Secondary hypertension takes a share of 5-20\% of hypertension cases and has different causative factors that could be preventable [1].

Hypertension is a leading risk factor of mortality, followed by tobacco use and diabetes mellitus (DM). It is the fifth cause of Disability-adjusted life years (DALYs) lost

\footnotetext{
*Correspondence: melese_chego@yahoo.com

1 Department of Public Health, Institute of Health Sciences, Wollega University, Nekemte, Ethiopia

Full list of author information is available at the end of the article
}

globally [3]. Hypertension doubles the risk of CVD: coronary heart disease (CHD), congestive heart failure (CHF), ischemic stroke and hemorrhagic stroke, renal failure and Peripheral arterial disease (PAD). Systolic blood pressure causes $51 \%$ and $45 \%$ of deaths due to stroke and ischemic heart disease respectively [1-3].

Hypertension has been thought of as a disease of affluence. But, now its distribution is increasing in Africa than in Europe and America [4]. The global average of the prevalence of hypertension is about $40 \%$. Its distribution is different in different regions, being highest in Africa; $46 \%$ [2]. The prevalence of undiagnosed, untreated, and uncontrolled hypertension; and the risk of hypertensionrelated morbidities are higher in developing countries than the high-income countries $[2,4,5]$.

Morbidity and mortality caused by chronic illnesses are increasing in developing countries; shifting from 
communicable diseases to non-communicable diseases $[6,7]$. According to the world health (WHO) report, $67 \%$ of mortality in low and middle-income countries was attributed to non-communicable diseases of which CVD shares 48\% [5]. Hypertension is the leading cause of CVD and related mortality in Africa in the coming few years. The WHO survey in 20 African countries shows that the prevalence of hypertension is 19.3 to $39.6 \%[6,7]$. Evidence shows an increase in hypertension and related complications in Ethiopia [8-10].

The distribution of hypertension can be affected by different modifiable and non-modifiable factors: family history of hypertension, age, lifestyle and environmental factors [11-15]. Another behavioral factor, which became rampant in Ethiopia and could be related to hypertension is frequent chewing of khat. According to research done in Addis Ababa, Current daily smoking and regular khat chewing were significantly associated with elevated mean diastolic blood pressure [15]. Psychological factors such as anxiety, depression, and anger contribute to the development of hypertension [16-19]. This study intended to determine the prevalence of hypertension; and the physical, behavioral and sociodemographic determinants of hypertension among adult populations in the study area.

\section{Main text \\ Methods \\ Study setting and design}

A community-based crosssectional study was conducted from November 1 to December 30, 2015; on the adult population aged 18 and above, residing in Nekemte town. The required sample size of the study was 711 and was determined using a single finite population proportion formula. The assumptions were; the prevalence of hypertension $30 \%$, a non-response rate of $10 \%$ and a design effect of 2.

$$
\mathrm{n}=\frac{\left(\mathrm{Z}_{\alpha / 2}\right) \mathrm{p}(1-\mathrm{p})}{\mathrm{d}^{2}}
$$

\section{Sampling procedure}

The study participants were identified by a multistage sampling technique.

\section{Variables}

Dependent variable The Prevalence of hypertension.

Independent variable Age, Sex, Ethnicity, marital status, educational status, family Income, accessibility of Screening program, alcohol consumption, smoking, chewing khat, diet, physical exercise, and psychological stress.

\section{Data collection procedure}

Data were collected by 5 health extension workers and supervised by experienced BSc nurses after 1-day training. Data were obtained on hypertension status, socio-demographic characteristics and behavioral factors by interview and measurement as appropriate. Weight, height, waist circumference, and blood pressure were taken by Physical measurement. Weight and height were measured on the participant's standing position without a shoe. Height was recorded to the nearest $0.5 \mathrm{~cm}$, and weight was measured to the nearest $100 \mathrm{~g}$ with a digital weight scale. BMI was calculated as weight in kilograms divided by height in meters squared [weight $(\mathrm{kg}) /(\text { height }(\mathrm{m}))^{2}$ ]. Waist circumference was measured at the midway between the level of the iliac crest and lowest margin of the rib by a non-elastic tape measure. Blood pressure was measured in a sitting position with supported back, and a mercury sphygmomanometer and a stethoscope were used to measure the BP. The accuracy of the mercury sphygmomanometer was checked on the upper curve of the meniscus of the mercury column. It should be fixed at $0 \mathrm{mmHg}$, free of dirt, and rises and falls freely during cuff inflation and deflation. Standard procedure was used to measure BP: stereoscope placed 2-3 cm above ante-cubital fossa and the bladder encircled at least $2 / 3 \mathrm{rd}$ of the arm. The participants took rest for at least $5 \mathrm{~min}$ before measurement. They did not drink coffee, smoke cigarette and engaged in strenuous exercise within an hour of BP measurement. The measurement was done in both arms at sitting position with back supported and the larger one was taken. Two consecutive measurements of BP were taken 2 min apart from the participants, and the average reading was used for analysis $[20,21]$.

\section{Data processing and analysis}

Data were cleaned and entered into a computer and analyzed using SPSS Windows Version 20. Descriptive analysis was done using numbers and percentages. The presence of a statistical association between dependent and independent variables was assessed. Multiple Logistic regression analysis was done to assess independent risk factors for hypertension.

\section{Result \\ Socio-demographic and socio-economic characteristics of respondents}

Seven hundred five (with a response rate of 99.2\%) participants were included in this study making 99.2 response rate. The mean $( \pm \mathrm{SD})$ age of the participants was $33.24 \pm 0.942$ years with a maximum of 80 and a minimum of 18 years. The majority (78.3\%) of them were within the 1st age group (18-40 years). More than half 
of the respondents $(61.6 \%)$ were females. The majority of the respondents $(64 \%)$ were protestant Christians. In Ethnicity, Oromo constitute the majority of the respondents; $89.8 \%$ (Table 1).

\section{Prevalence of hypertension}

The mean systolic and diastolic BP readings were 119.8 $( \pm 1.2)$ and $81.9( \pm 0.9) \mathrm{mmHg}$, respectively. The overall prevalence of hypertension was $34.9 \%( \pm 3.6 \% \mathrm{CI}$

Table 1 Sociodemographic characteristics of respondents in Nekemte town, western Ethiopia, Dec. 2015 ( $n=705)$

\begin{tabular}{|c|c|c|}
\hline Variables & Frequency (in N) & $\begin{array}{l}\text { Percentage } \\
\text { (in \%) }\end{array}$ \\
\hline \multicolumn{3}{|l|}{ Age groups (year) } \\
\hline $18-40$ & 552 & 78.3 \\
\hline $41-64$ & 127 & 18.0 \\
\hline$\geq 65$ & 26 & 3.7 \\
\hline \multicolumn{3}{|l|}{ Sex } \\
\hline Male & 271 & 38.4 \\
\hline Female & 434 & 61.6 \\
\hline \multicolumn{3}{|l|}{ Religion } \\
\hline Protestant christian & 451 & 64.0 \\
\hline Orthodox christian & 220 & 31.2 \\
\hline Muslim & 24 & 3.4 \\
\hline Catholic christian & 2 & 0.3 \\
\hline Wakefeta & 8 & 1.1 \\
\hline \multicolumn{3}{|l|}{ Ethnicity } \\
\hline Oromo & 633 & 89.8 \\
\hline Amharic & 60 & 8.5 \\
\hline Gurage & 6 & 0.9 \\
\hline Tigre & 4 & 0.6 \\
\hline Others & 2 & 0.3 \\
\hline \multicolumn{3}{|l|}{ Education status } \\
\hline No formal education & 75 & 10.7 \\
\hline Primary school & 119 & 16.9 \\
\hline Secondary school & 320 & 45.5 \\
\hline College and above & 189 & 26.9 \\
\hline \multicolumn{3}{|l|}{ Marital status } \\
\hline Never married & 253 & 35.7 \\
\hline Currently married & 392 & 55.6 \\
\hline Divorced & 14 & 2.0 \\
\hline Widowed & 45 & 6.4 \\
\hline \multicolumn{3}{|l|}{ Occupation } \\
\hline Gov. employee & 150 & 21.2 \\
\hline NGO employee & 44 & 6.3 \\
\hline Self-employed & 195 & 27.7 \\
\hline Student & 194 & 27.6 \\
\hline Homemaker & 10 & 1.4 \\
\hline Retired & 15 & 2.1 \\
\hline Unemployed & 98 & 13.8 \\
\hline
\end{tabular}

31.3-38.5). About 37\% (36.9\%) of males and 33\% of females were hypertensive. Only $53.3 \%$ of respondents had BP measurement before. Out of hypertensive respondents; only $52.7 \%$ knew as their BP is raised and only $22.4 \%$ were on anti-hypertensive medications.

\section{Descriptions of behavioral, physical and nutritional factors}

Only $1.4 \%$ of the respondents have ever smoked cigarettes, $13.9 \%$ had regular alcohol drinking habits, and $6.2 \%$ had cat chewing habits. On dietary behavior, most of the respondents $(83.6 \%)$ had a habit of high Salt consumption. Only $3.2 \%$ and $5.3 \%$ of the respondents had a habit of adequate intake of vegetables and fruit respectively. As to physical exercise; $18 \%$ of them were engaged in rigorous physical activity, $52.2 \%$ of them were engaged in moderate activities and $29.8 \%$ were not involved in either of these activities. As to the BMI, 62.6\%, 16.7\%, $11.2 \%$, and $9.5 \%$ were in the normal range, underweight, overweight and obese respectively. About $21.6 \%$ of the obese had central obesity.

\section{Risk factors associated with hypertension}

To identify factors associated with the prevalence of hypertension, age, sex, occupation, income, educational status, BMI, family history of hypertension, smoking, alcohol consumption, sedentary lifestyle and khat chewing status were entered in bivariate logistic regression analyses. Accordingly, age, BMI, sedentary lifestyle, education status, family history of hypertension, self-history of Diabetes mellitus (DM), alcohol drinking status and Khat chewing were significantly associated with the prevalence of hypertension. However, in multivariate logistic regression, only age, BMI, educational status and Khat chewing were associated with the prevalence of hypertension (Table 2).

\section{Discussion}

This study has revealed that about a third of the adult population in the town were hypertensive. This is comparable with the WHO estimate of the prevalence of hypertension in Ethiopia which is $31 \%$. The result is higher than a similar study done in the Northern part of the country; (28\%) and it is comparable with the study done elsewhere $[8-10,22]$. The finding is higher compared to surveys in Eritrea (16\%), and Ghana (29.4\%) [23, 24]. However, this study showed a lower prevalence of hypertension compared with the WHO estimate of the prevalence of hypertension in Africa, which is 46\% [5]. The variation can be explained by; variability in different age groups, the prevalence in different proven risk factors, the difference in the definition of hypertension and genetic differences. 
Table 2 Multiple logistic regression analysis of factors associated with hypertension among respondents in Nekemte town, western Ethiopia, Dec. $2015(\mathrm{n}=705)$

\begin{tabular}{|c|c|c|c|c|}
\hline \multirow[t]{2}{*}{ Variables } & \multicolumn{2}{|c|}{ Hypertension } & \multirow[t]{2}{*}{ COR $(95 \% \mathrm{Cl})$} & \multirow[t]{2}{*}{ AOR $(95 \% \mathrm{Cl})$} \\
\hline & Yes (\%) & No (\%) & & \\
\hline \multicolumn{5}{|l|}{ Age group (year) } \\
\hline $18-40$ & $156(28.3 \%)$ & $396(71.7 \%)$ & 1 & 1 \\
\hline $41-64$ & $70(55.1 \%)$ & $57(44.9 \%)$ & $3.12(2.1,4.63)$ & $2.6(1.49,4.57)$ \\
\hline$\geq 65$ & $20(76.9 \%)$ & $6(23.1 \%)$ & $8.47(3.33,21.28)$ & $5.85(1.72,20)$ \\
\hline \multicolumn{5}{|l|}{ BMI } \\
\hline Normal & 148 (33.6\%) & $293(66.4 \%)$ & 1 & 1 \\
\hline Underweight & $16(20.3 \%)$ & $63(79.7 \%)$ & $0.63(0.45,0.9)$ & $0.48(0.22,1.05)$ \\
\hline Overweight/ & $82(44.3 \%)$ & $55.7(55.7 \%)$ & $3.14(1.69,5.83)$ & $1.71(1.09,2.67)$ \\
\hline \multicolumn{5}{|l|}{ Obese } \\
\hline \multicolumn{5}{|l|}{ Central obesity } \\
\hline Yes & $74(48.7 \%)$ & $78(51.3 \%)$ & $2.1(1.46,3.03)$ & \\
\hline No & $172(31.1 \%)$ & $381(68.9 \%)$ & 1 & \\
\hline \multicolumn{5}{|l|}{ Exercise level } \\
\hline Vigorous & $34(26.8 \%)$ & $93(73.2 \%)$ & 1 & 1 \\
\hline Moderate & $128(34.8 \%)$ & $240(65.2 \%)$ & $1.46(0.93,2.28)$ & $0.85(0.48,1.5)$ \\
\hline None & $84(40 \%)$ & $126(60 \%)$ & $1.82(1.13,2.95)$ & $1.11(0.57,2.14)$ \\
\hline \multicolumn{5}{|l|}{ Alcohol intake ever } \\
\hline Yes & $45(45.9 \%)$ & $53(54.1 \%)$ & $1.72(1.11,2.64)$ & $0.94(0.5,1.78)$ \\
\hline No & 201 (33.1\%) & $406(66.9 \%)$ & 1 & 1 \\
\hline \multicolumn{5}{|l|}{ Chewed Khat past year } \\
\hline Yes & $24(54.5 \%)$ & $20(45.5 \%)$ & 1 & 1 \\
\hline No & $222(33.6 \%)$ & $439(66.4 \%)$ & $2.38(1.28,4.39)$ & $2.44(1.05,5.68)$ \\
\hline \multicolumn{5}{|l|}{ Monthly income (ETB) } \\
\hline$<1500$ & $59(27.2 \%)$ & $158(72.8 \%)$ & 1 & \\
\hline $1500-4000$ & 100 (41.3\%) & $142(58.7 \%)$ & $1.89(1.27,2.79)$ & \\
\hline $4000-6000$ & $20(60.6 \%)$ & $13(39.4 \%)$ & $4.12(1.93,8.77)$ & \\
\hline$\geq 6000$ & $12(26.7 \%)$ & $33(27.3 \%)$ & $0.97(0.48,2.01)$ & \\
\hline \multicolumn{5}{|l|}{ Education status } \\
\hline No formal education & $53(70.7 \%)$ & $22(29.3 \%)$ & 1 & 1 \\
\hline Primary complete & $45(37.8 \%)$ & $74(62.2 \%)$ & $3.96(2.13,7.36)$ & $1.63(0.72,3.69)$ \\
\hline Secondary complete & $97(30.3 \%)$ & $223(69.7 \%)$ & $5.52(3.19,9.61)$ & $2.38(1.11,5.09)$ \\
\hline College and above & 49 (25.9\%) & $140(74.1 \%)$ & $6.88(3.8,12.47)$ & $2.75(1.26,6.03)$ \\
\hline \multicolumn{5}{|l|}{ Self-report of DM } \\
\hline Yes & $14(53.8 \%)$ & $12(46.2 \%)$ & $2.25(1.02,4.95)$ & $1.75(0.625,4.88)$ \\
\hline No & $232(34.2 \%)$ & 447 (65.8\%) & 1 & 1 \\
\hline \multicolumn{5}{|l|}{ Family history of HTN } \\
\hline Yes & 123 (44.2\%) & 155 (55.8) & $1.40(1.02,1.92)$ & $1.34(0.88,2.03)$ \\
\hline No & 151 (35.4\%) & $276(64.6 \%)$ & 1 & 1 \\
\hline
\end{tabular}

In this study; age, BMI, educational status and Khat chewing had a positive association with the prevalence of hypertension. With regards to sex, similar to studies done in Gondar, Addis Ababa, Durame and Bedele towns of Ethiopia, it didn't show any association [8-10]. The prevalence of hypertension was higher in overweight and obese (44.3\%) than those of normal (33.6\%) and underweight (20.3\%). This is consistent with other studies [8-10]. In this study, chewing Khat in the past 1 year (54.5\%) had an association with hypertension. This is similar to the study done in Addis Ababa but did not show any association with a study done in Bedele [10, 15]. 


\section{Conclusion}

The prevalence of hypertension was found to be high among adults older than 18 years in Nekemte town. Older age, higher educational status, overweight/obesity, and Khat chewing were associated with a high prevalence of Hypertension. Community-based health promotion and screening programs should be strengthened and further researches with biochemical data should be done to control the impacts.

\section{Limitation}

There could be a recall bias on responses to behaviors. Hiding of socially unacceptable behaviors like alcohol intake; cigarette smoking and Khat chewing may underestimation of the finding. This study did not include the biochemical factors of hypertension.

\section{Abbreviations}

BP: blood pressure; DALYs: disability-adjusted life years; CVD: cardiovascular disease; CHF: congested heart disease; WHO: World Health Organization; BMI: body mass index; DM: diabetes mellitus.

\section{Acknowledgements}

We extend appreciation to the Wollega university department of public health, for allowing us to conduct this research. We are also thankful to the Nekemte town administration for the support in the collection of data. Above all, the respondents deserve appreciation for their cooperation.

\section{Authors' contributions}

All of the authors participated in the preparation of this manuscript. The final version of the manuscript was read by all authors and approved for the publication process. GTG generated the research question, developed the proposal, supervised the data collection process, analyzed data and prepared the research report. MCC was the senior advisor of the research proposal development and data analysis process. EMR was co-advisor of the research proposal development and data analysis process. All authors read and approved the final manuscript.

\section{Funding}

The source of funds for this study was the authors.

\section{Availability of data and materials}

The data sets during and/or analyzed during the current study available from the corresponding author on reasonable request.

\section{Ethics approval and consent to participate}

Ethical clearance was obtained from Wollega University ethical clearance committee before data collection. Written informed consent was obtained from all participants for participation in this research.

\section{Consent for publication}

Not applicable.

\section{Competing interests}

The authors declare that they have no competing interests.

\section{Author details}

${ }^{1}$ Department of Public Health, Institute of Health Sciences, Wollega University, Nekemte, Ethiopia. ${ }^{2}$ Nekemte Specialized Hospital, Nekemte, Oromia Regional State, Ethiopia.
Received: 4 September 2019 Accepted: 12 November 2019

Published online: 21 November 2019

\section{References}

1. Longo D, Kasper D. Harrison's principles of internal medicine, vol. 2. 18th ed. 2011. https://freemecal.com/harrisons-principles-of-internal-medic ine-18th-edition-pdf.

2. Mathers C, Stevens G, Mascarenhas M. Global health risks: mortality and burden of disease attributable to selected major risks. Geneva: World Health Organization; 2009.

3. Weber MA, et al. Practice guidelines for the management of hypertension in the community. J Clin Hypertens. 2014. https://doi.org/10.1111/ jch.12237.

4. van de Vijver $\mathrm{S}$, Akinyi $\mathrm{H}$, Oti S, Kyobutungi $\mathrm{C}$. The impact of non-communicable diseases (NCDs) and neglected tropical diseases (NTDs) on development in Africa. In: AU conference of ministers of health (camh6) sixth ordinary session, 22-26 April 2013, Addis Ababa, Ethiopia.

5. World Health Organization. A global brief on hypertension: silent killer, a global public health crisis. Geneva: WHO; 2013. https://www.who.int/ cardiovascular_diseases/publications/global_brief_hypertension/en/.

6. van de Vijver S, et al. Status report on hypertension in Africa-consultative review for the 6 th Session of the African Union Conference of Ministers of Health on NCDs. Pan Afr Med J. 2013;16:38. https://doi. org/10.11604/pamj.2013.16.38.3100.

7. Addo J, Smeeth L, Leon DA. Hypertension in sub saharan Africa: a systematic review. Hypertension. 2007. https://doi.org/10.1161/HYPERTENSI ONAHA.107.093336.

8. Tesfaye F, Byass P, Wall S. Population-based prevalence of high blood pressure among adults in Addis Ababa: uncovering a silent epidemic BMC Cardiovasc Disord. 2009;9:39.

9. Helelo TP, Gelaw YA, Adane AA. Prevalence and associated factors of hypertension among adults in Durame Town, Southern Ethiopia. PLoS ONE. 2014:9(11):e112790. https://doi.org/10.1371/journal.pone.0112790.

10. Gudina $K$, et al. Prevalence of hypertension and associated factors in Bedele town, Southwest Ethiopia. Ethiop J Health Sci. 2014;24(1):21-6. https://doi.org/10.4314/ejhs.v24i1.3.

11. Wang NY, et al. Blood pressure change and risk of hypertension associated with parental hypertension. Arch Intern Med. 2008;168:643-8.

12. Awoke A, et al. Prevalence and associated factors of hypertension among adults in Gondar, northwest Ethiopia. BMC Cardiovasc Disord. 2012;12:113.

13. World Health Organization. Global health observatory data repository. http://apps.who.int/gho/data/view.main. Accessed 11 Feb 2013.

14. Appel $L$, et al. Effects on blood pressure of reduced dietary sodium and the dietary approaches to stop hypertension (DASH) diet. N Engl J Med. 2001;344(1):3-10.

15. Tesfaye F, et al. Association of smoking and Khat use with high blood pressure among adults in Addis Ababa, Ethiopia. 2006. http://www.cdc. gov/pcd/issues/2008/jul/07_0137.htm.

16. Rozanski A, et al. The epidemiology, pathophysiology, and management of psychosocial risk factors in cardiac practice: the emerging field of behavioral cardiology. J Am Coll Cardiol. 2005;45:637-51.

17. Yan LL, et al. Psychosocial factors and risk of hypertension: the coronary artery risk development in young adults. JAMA. 2003;290:2138-48.

18. Rutledge T, Hogan BE. A quantitative review of prospective evidence linking psychological factors with hypertension development. Psychosom Med. 2002;64:758-66.

19. Williams RB, et al. Psychosocial risk factors for cardiovascular disease. JAMA. 2003;290(16):2190-2.

20. Bonita R, de Courten M, Dwyer T, Jamrozik K, Winkelmann R. Surveillance of risk factors for noncommunicable diseases: the WHO STEP wise approach. Geneva, Switzerland: World Health Organization; 2002. http:// www.sciepub.com/reference/35088.

21. Pickering TG, et al. Recommendations for blood pressure measurement in humans and experimental animals. Circulation. 2005. https://doi. org/10.1161/01.HYP.0000150859.47929.8e.

22. Wamala JF, Karyabakabo Z, Ndungutse D, Guwatudde D. Prevalence and factors associated with hypertension in Rukungiri district, Uganda-a community-based study. Afr Health Sci. 2009;9(3):153-60. 
23. Mufunda J, Mebrahtu G, Usman A, Nyarango P, Kosia A, Ghebrat Y, Ogbamariam A. The prevalence of hypertension and its relationship with obesity: results from a national blood pressure survey in Eritrea. J Hum Hypertens. 2006;20(1):59-65.

24. Agyemang C, Bruijnzeels MA, Owusu-Dabo E. Factors associated with hypertension awareness, treatment, and control in Ghana, West Africa. J Hum Hypertens. 2006;20:67-71.

\section{Publisher's Note}

Springer Nature remains neutral with regard to jurisdictional claims in published maps and institutional affiliations.
Ready to submit your research? Choose BMC and benefit from:

- fast, convenient online submission

- thorough peer review by experienced researchers in your field

- rapid publication on acceptance

- support for research data, including large and complex data types

- gold Open Access which fosters wider collaboration and increased citations

- maximum visibility for your research: over $100 \mathrm{M}$ website views per year

At BMC, research is always in progress.

Learn more biomedcentral.com/submissions 